\title{
Cardiovascular disease risk in people with spinal cord injury: is there a possible association between reduced lung function and increased risk of diabetes and hypertension?
}

\author{
BF Köseoğlu ${ }^{1}$, VB Safer ${ }^{2}$, Ö Öken ${ }^{1}$ and S Akselim ${ }^{1}$
}

\begin{abstract}
Study design: Retrospective, descriptive study of medical files 253 patients with chronic traumatic spinal cord injury (SCI).
Objectives: To determine the frequency of cardiovascular disease (CVD) risk factors in SCl people, to estimate CVD risk in this population according to the Framingham Risk Score (FRS) and to determine whether reduced lung function parameters are significant predictors of diabetes mellitus (DM) and hypertension.
\end{abstract}

Setting: Academic Rehabilitation Hospital.

Methods: Demographic and clinical records of the patients and lung function parameters were obtained.

Results: The FRS could not be calculated in $26(10.3 \%)$ patients because this tool is designed for adults aged 20 years and older. According to the FRS guideline, 6.7\% of the SCl patients had high risk, $5.9 \%$ of them had intermediate risk and $77.1 \%$ of the study group had low risk for CVD. Regression analysis showed that impaired lung function parameters (FEV1, FVC and MVV) were significant predictors for the future development of hypertension (odds ratio (OR): 0.483 (0.258-0.903 95\% confidence interval (Cl)), OR: 0.549 $(0.319-0.94695 \% \mathrm{Cl})$ and OR: $0.981(0.965-0.998$ 95\% Cl), respectively) and DM (OR: $0.335(0.140-0.801$ 95\% Cl), OR: 0.391 $(0.183-0.83995 \% \mathrm{Cl})$ and $\mathrm{OR}: 0.970(0.947-0.99395 \% \mathrm{Cl})$, respectively) in the $\mathrm{SCl}$ population.

Conclusion: This study showed that there might be a significant relationship between reduced lung function and the risk of DM and hypertension in people with $\mathrm{SCl}$. Therefore, systematic measurement of these parameters should be performed in the routine clinical follow-up of SCl patients. Once reduced lung parameters are determined, the higher risk for developing hypertension and DM should be considered.

Spinal Cord (2017) 55, 87-93; doi:10.1038/sc.2016.101; published online 5 July 2016

\section{INTRODUCTION}

Increased long-term survival in the spinal cord injury (SCI) population brings an onset of new medical problems that were not present at the time of injury. Early onset of cardiovascular disease (CVD) and premature coronary heart disease (CHD) have been observed in this population. ${ }^{1-5}$ Combined, ischemic and nonischemic heart disease is the most common cause of death in these people at least 1 year post injury, accounting for $\sim 40 \%$ of the deaths. ${ }^{2,3,5-7}$ Therefore, early identification, prevention and management of CVD risk factors are important in order to reduce CVD mortality and morbidity in people with SCI.

Physical inactivity and reduced aerobic fitness, decreased lean body mass and increased adiposity, abnormal glucose homeostasis and increased prevalence of diabetes mellitus (DM), abnormal lipoprotein profiles with elevated low-density lipoprotein, triglycerides and total cholesterol levels, and lower high-density lipoprotein (HDL), abnormal hemostatic and inflammatory markers, and increased activation of the renin-angiotensin-aldosterone system and hypertension are suggested as specific risk factors for CVD in this population. ${ }^{3-6}$

Respiratory dysfunction is also an important cause of morbidity and mortality in people with SCI. ${ }^{8-12}$ Denervation of the respiratory pump (reduced respiratory muscle force and fatigue), impaired cough, increased secretions and bronchial tone, and reduced chest wall and lung compliance are the causes for respiratory dysfunction and complications seen in this population., ${ }^{8,912}$ Because of reduced inspiratory muscle force, lung volumes and flow rates including forced vital capacity (FVC) and forced expiratory volume in $1 \mathrm{~s}$ (FEV1) are diminished immediately after the injury. $8,9,12,13$

In the general population, there is strong evidence that people with lower lung function measures (in the absence of overt respiratory symptoms or disease) have a higher risk for developing DM and hypertension. ${ }^{4,14-22}$ Lung function predicts the development of insulin resistance or $\mathrm{DM},{ }^{14,15,20,21}$ and it is also a useful predictor of subsequent development of hypertension in able-bodied people. ${ }^{16-18,22,23}$ Although CVD is a major cause for mortality in the SCI population, it is not yet known whether the same association between reduced lung function and future development of DM and hypertension exists in people with SCI.

The major CVD risk factors for able-bodied individuals are hypertension, cigarette smoking, family history of premature CVD, age and low HDL level. ${ }^{2-4,6,24}$ Furthermore, DM is regarded as a CHD equivalent. ${ }^{24}$ Nearly all risk factors for CVD have been found to

\footnotetext{
${ }^{1}$ Department of Physical Medicine and Rehabilitation, Ministry of Health, Ankara Physical Medicine and Rehabilitation Training and Research Hospital, Ankara, Turkey and ${ }^{2}$ Department of Physical Medicine and Rehabilitation, Ministry of Health, Istanbul Haydarpasa Numune Training and Research Hospital, Istanbul, Turkey

Correspondence: Dr BF Köseoğlu, Department of Physical Medicine and Rehabilitation, Ministry of Health, Ankara Physical Medicine and Rehabilitation Training and Research Hospital, Baris Sitesi 2160.sok No: 1, Bilkent Kavsagi, Ankara 06530, Turkey.

E-mail: fkoseoglu28@gmail.com

Received 17 December 2015; revised 9 May 2016; accepted 28 May 2016; published online 5 July 2016
} 
be more prevalent in SCI subjects compared with able-bodied subjects. ${ }^{1-4,6,20}$

The Framingham Risk Score (FRS) is a widely accepted global risk algorithm using multiple risk factors such as age, sex, total cholesterol, HDL, smoking, systolic blood pressure and the use of blood pressure medication to estimate the 10-year CHD event risk in individuals not previously diagnosed with heart disease. ${ }^{5}$ FRS is a valid score for CVD risk estimation and has been used in multiple ethnic group investigations, as well as in the SCI population. . $^{1,25-27}$

The aims of this study were to determine the frequency of CVD risk factors in people with chronic traumatic SCI, to estimate CHD risk in this population according to the Framingham risk model and to determine whether reduced lung function measures are significant predictors of DM and hypertension.

\section{MATERIALS AND METHODS}

\section{Participants}

Two-hundred and fifty-three patients with chronic traumatic SCI (duration of $>20$ months) who were admitted to the inpatient rehabilitation department of an academic rehabilitation hospital between January 2010 and July 2014 were retrospectively studied. Ankara Physical Medicine and Rehabilitation Training and Research Hospital is located in the Turkey's capital. This institution is a center of excellence, providing comprehensive rehabilitation services (with 300 beds for inpatients) to the patients needing rehabilitation interventions, as it is the biggest inpatient rehabilitation hospital of Turkey, where patients from all over the country are accepted.

The patients with SCI who had known hypertension, impaired fasting glucose or DM, low HDL level or dyslipidemia and CVD before traumatic injury were excluded from the analysis. The patients who had SCI due to reasons other than trauma were also excluded.

The protocol for the study was approved by the local research ethics committee.

\section{Data collection}

Sixty-nine females and 184 males (with a mean age of $35.7 \pm 14.4$ years) were included in this study. An experienced Physical Medicine and Rehabilitation Specialist reviewed all clinical records and the routine laboratory measurements that were obtained in the first week of the patient's admission to the hospital.

The data collected for each patient included the patients' demographic features, time since injury, neurologic level of injury, completeness of the lesion, type of SCI score-paraplegia versus quadriplegia, American Spinal Injury Association Impairment Scale (AIS) score, ambulation level (wheelchair- dependent or ambulate with orthosis), systolic and diastolic blood pressure and the presence of hypertension (antihypertensive use or newly diagnosed at entry), fasting blood glucose and the presence of DM (use of any hypoglycemic agents or newly diagnosed at entry), electrocardiographic (ECG) abnormalities, the level of C-reactive protein (CRP), smoking status, the level of serum HDL and the body mass index (BMI). The clinical records including a history of CHD, peripheral arterial disease, abdominal aortic aneurysm and symptomatic carotid artery disease, pulmonary emboli and deep venous thrombosis were also recorded.

\section{Risk factors}

Hypertension was defined as an elevated blood pressure of $140 \mathrm{~mm} \mathrm{Hg}$ systolic and/or $90 \mathrm{~mm} \mathrm{Hg}$ diastolic ${ }^{24}$ or being on an antihypertensive treatment. A fasting glucose level higher than $110 \mathrm{mg} \mathrm{dl}^{-1}$ according to the report of the Expert Committee on the Diagnosis and Classification of $\mathrm{DM}^{28}$ or the use of an antidiabetic treatment was considered as diagnostic for impaired fasting glucose and DM. Low HDL level was defined as less than $40 \mathrm{mg} \mathrm{dl}^{-1}$. $^{24}$

The BMI was calculated as weight $(\mathrm{kg}) /$ height $^{2}\left(\mathrm{~m}^{2}\right)$ for each patient.The SCI population has no specific definition for overweight and obesity. ${ }^{1,29}$ The prevalence of overweight (a proportion of the patients with a BMI of $25 \mathrm{~kg} \mathrm{~m}^{-2}$ or higher) and obese (a proportion of the patients with a BMI of $30 \mathrm{~kg} \mathrm{~m}^{-2}$ or higher) in the study population was determined using the calculated BMI.

\section{Lung function}

The Lung Function data including FVC, FEV1 and maximum voluntary ventilation (MVV) were obtained by the application of the spirometry system procedures using a hand-held spirometer (Sensormedix, Vmax29, Yorba Linda, CA, USA) during the first week upon the patient's admission to the hospital. The measurements were expressed as percentages of the normal predicted values. Eighty percent of the predicted maximum or greater were accepted as normal.

\section{Framingham risk score}

The FRS was used to represent a SCI patient's 10-year risk for having a CHD. ${ }^{1,25,26}$ The FRS was calculated on a web-based calculator (http://cvdrisk. nhlbi.nih.gov). This CHD risk tool is designed for adults aged 20 and older. The FRS groups were defined by risk percentages (i.e. Low $<10 \% \mathrm{CHD}$ 10 -year risk, intermediate $>10$ and $<20 \%$ CHD 10-year risk, high $>20 \%$ CHD 10-year risk or DM).

\section{Statistical analyses}

The data were analyzed using SPSS 20.0 for Windows (SPSS, Chicago, IL). The frequency and descriptive statistics were calculated. The descriptive statistics were presented as mean \pm s.d. for the continuous variables, whereas they were presented as median (min-max) for the categorical variables. The medical records for the BMI could not be found for 60 patients. For those patients without the BMI scores, the single imputation method was used by mean substitution. The missing values of BMI were replaced with the sample mean in this method.

The relationships among DM, hypertension, HDL, FRS and the patients' demographic and the clinical variables were analyzed using the Spearman's correlations coefficients. Age, sex, the neurologic level of injury, completeness of the lesion, the type of SCI score, the AIS score, ambulation level, BMI, CRP and lung function parameters including FVC, FEV1 and MVV were used as independent variables to assess their predictability on the development of hypertension, DM and low serum HDL in the logistic regression analysis. A multiple linear regression analysis was also used to investigate the influence of the same independent variables to predict FRS. Stepwise backward method was used in logistic and multiple linear regression analysis.

\section{Results}

The clinical and demographic characteristics of the SCI subjects are shown in Table 1 and laboratory findings and pulmonary function test measurements are shown in Table 2.

Hypertension was present in 33 patients (13.0\%). Impaired fasting glucose and DM were observed in 23 patients (9.1\%). Most of our patients (85\%) had a low HDL level. Twenty-two (8.7\%) patients were under an antihypertensive treatment; $13(5.1 \%)$ patients were using antidiabetics, whereas $1(0.4 \%)$ of them was receiving a lipid-lowering drug. Also, 55 (21.7\%) patients were following a low-saturated-fat and low-cholesterol diet; 48 (18.9\%) patients were performing physical activities, and $80(31.6 \%)$ of them were applying weight control as other types of therapeutic intervention for CVD after the traumatic injury period.

The FRS could not be calculated in $26(10.3 \%)$ patients because this tool is designed for adults aged 20 years and older. According to the FRS guideline, $\sim 6.7 \%$ of the SCI patients had high risk, $5.9 \%$ of them had intermediate risk and $77.1 \%$ of the study group had low risk for CVD. Nearly $12.6 \%$ of our patients were identified as requiring therapeutic intervention for CVD.

A total of 80 patients $(31.6 \%)$ were overweight and obese. The mean CRP was $1.15+2.28$. Of all patients with SCI, $30 \%$ of them had higher CRP levels. One hundred forty-one $(55.7 \%)$ SCI patients had reduced MVV, whereas 162 patients (64\%) had reduced FVC and $136(53.7 \%)$ of the study group had reduced FEV1 values.

Table 3 shows the univariate correlations among clinical/demographic variables and HT, DM, low HDL level and FRS. A regression analysis was conducted to investigate whether clinical and demographic variables impact hypertension, DM, HDL and FRS in our patients. The age, BMI, ambulation level, MVV, FEV1 and FVC were significant predictors of DM (Table 4) and the age, BMI, MVV, FEV1 and FVC were significant predictors of hypertension 
Table 1 The Clinical and demographic characteristics of the patients

Patients $(n=253)$

$$
\begin{aligned}
& \text { Gender (n, \%) } \\
& \text { Female } \\
& \text { Male } \\
& B M I(\mathrm{n}, \%) \\
& <18 \\
& \text { 18-24.9 } \\
& >25 \\
& \text { Missing }
\end{aligned}
$$$$
\text { Age (years; mean } \pm \text { s.d.) }
$$$$
35.7 \pm 14.4
$$$$
\text { BMI (kg m-2; mean } \pm \text { s.d.) }
$$$$
69(27.3 \%)
$$$$
184(72.7 \%)
$$$$
23.9 \pm 4.5
$$

Time since injury (months; mean \pm s.d.)

$23(9.1 \%)$

$90(35.6 \%)$

$80(31.6 \%)$

$60(23.7 \%)$

$51.8 \pm 52.07$

AIS score (n, \%)

$$
\text { A }
$$$$
\text { B }
$$$$
\text { C }
$$$$
\text { D }
$$

$99(39.1 \%)$
$44(17.4 \%)$
$69(27.3 \%)$
$41(16.2 \%)$

Completeness of the lesion ( $\mathrm{n}, \%)$

Complete

Incomplete

$99(39.1 \%)$

$154(60.9 \%)$

Type of spinal cord injury score ( $\mathrm{n}, \%)$

Paraplegia

$185(73.1 \%)$

Tetraplegia

$68(26.9 \%)$

Neurologic level of injury (n, \%)

C4-8

$67(26.5 \%)$

T1-6

T7-12

$42(16.6 \%)$

$86(34.0 \%)$

L1-4

$58(22.9 \%)$

Ambulation level (n, \%)

\section{Ambulatory}

Non-ambulatory

$136(53.8 \%)$

$117(46.2 \%)$

Smoking status (n, \%)

$+$

$49(19.4 \%)$

$204(80.6 \%)$

Presence of hypertension ( $\mathrm{n}, \%$ )

$+$

$33(13.0 \%)$

$220(87.0 \%)$

Presence of $D M(\mathrm{n}, \%)$

$$
+
$$

$-$

History of CVD (n, \%)

\begin{tabular}{|c|c|}
\hline & Patients $(n=253)$ \\
\hline Fasting blood glucose (mg dl-1; mean \pm s.d.) & $91.39 \pm 17.09$ \\
\hline $\mathrm{SBP}(\mathrm{mm} \mathrm{Hg} ;$ mean \pm s.d. $)$ & $110.75 \pm 15.60$ \\
\hline $\mathrm{DBP}(\mathrm{mm} \mathrm{Hg} ;$ mean \pm s.d. $)$ & $70.63 \pm 9.61$ \\
\hline CRP (mg dl-1; mean \pm s.d.) & $1.15 \pm 2.28$ \\
\hline Median (min-max) & $0.49(0-17.60)$ \\
\hline Interquartile range & 0.60 \\
\hline HDL (mg dl-1; mean \pm s.d.) & $34.95 \pm 8.26$ \\
\hline $\mathrm{LDL}(\mathrm{mg} \mathrm{dl}-1 ;$ mean \pm s.d. $)$ & $105.24 \pm 30.80$ \\
\hline TC (mg dl-1; mean \pm s.d.) & $167.00 \pm 38.55$ \\
\hline TG (mg dl-1; mean \pm s.d.) & $134.25 \pm 80.32$ \\
\hline FEV1 (mean \pm s.d.) & $2.83 \pm 0.81$ \\
\hline FVC $($ mean \pm s.d. $)$ & $3.18 \pm 0.93$ \\
\hline MVV (mean \pm s.d.) & $96.46 \pm 31.19$ \\
\hline FRS (\%; mean \pm s.d.) & $4.16 \pm 6.39$ \\
\hline Median (min-max) & $1.0(1-30)$ \\
\hline Interquartile range & 3.0 \\
\hline \multicolumn{2}{|l|}{ FRS classification (n, \%) } \\
\hline$<10 \%$ & $195(77.1 \%)$ \\
\hline $10-20 \%$ & $15(5.9 \%)$ \\
\hline$>20 \%$ & $17(6.7 \%)$ \\
\hline Not applicable & $26(10.3 \%)$ \\
\hline
\end{tabular}

$$
\begin{array}{cc}
+ & 6(2.4 \%) \\
- & 247(97.6 \%)
\end{array}
$$

Abbreviations: AIS, American Spinal Injury Association Impairment Scale; BMI, body mass index; DM, diabetes mellitus; CVD, cardiovascular disease.

\begin{tabular}{|c|c|c|c|c|}
\hline & $H T$ & $D M$ & Low HDL level & FRS \\
\hline Age & $0.334^{* *}$ & $0.279 * *$ & 0.055 & $0.746^{* *}$ \\
\hline Sex & -0.165 & -0.292 & $0.820 * *$ & $0.172^{*}$ \\
\hline BMI & $0.291^{* *}$ & $0.185^{*}$ & 0.042 & $0.316^{* *}$ \\
\hline Time since injury & 0.023 & -0.016 & -0.116 & 0.049 \\
\hline Type of spinal cord injury score & 0.175 & 0.297 & -0.367 & -0.044 \\
\hline Completeness of the lesion & -0.297 & -0.113 & 0.124 & $-0.194^{*}$ \\
\hline AIS score & 0.261 & 0.038 & -0.166 & $0.240^{* *}$ \\
\hline Neurologic level of injury & 0.081 & 0.069 & $-0.358^{\star}$ & 0.088 \\
\hline Ambulation level & -0.121 & $-0.568^{* *}$ & $-0.530^{* *}$ & 0.005 \\
\hline FEV1 & $-0.192^{*}$ & $-0.213^{*}$ & 0.087 & $-0.226^{*}$ \\
\hline FVC & $-0.182^{*}$ & $-0.207^{\star}$ & 0.108 & -0.144 \\
\hline MVV & $-0.173^{*}$ & $-0.236^{*}$ & 0.129 & $-0.182^{*}$ \\
\hline CRP & 0.054 & $0.150^{*}$ & $0.141^{*}$ & $0.188^{*}$ \\
\hline
\end{tabular}

(Table 5). Furthermore, gender, neurologic level of C3-C8 and T1-T6, and ambulation level were significant predictors of a low HDL level (Table 6). Age, sex, the type of SCI score, the neurologic level of injury and MVV were significant predictors of FRS (Table 7).
Table 2 Laboratory findings and pulmonary function test measurements

Abbreviations: CRP, C-reactive protein; DBP, diastolic blood pressure; FEV1, forced expiratory volume in $1 \mathrm{~s}$; FRS, Framingham Risk Score; HDL, high-density lipoprotein; LDL, low-density lipoprotein; SBP, systolic blood pressure; TC, total cholesterol; TG, triglyceride.

Table 3 The univariate correlations among clinical/demographic variables and HT, DM, low HDL level and FRS

Abbreviations: AIS, American Spinal Injury Association Impairment Scale; BMI, body mass index; CRP, C-reactive protein; DM, diabetes mellitus; FEV1, forced expiratory volume in $1 \mathrm{~s}$; FRS, Framingham Risk Score; FVC, forced vital capacity; HDL, high-density lipoprotein; $\mathrm{HT}$, hypertension; MVV, maximum voluntary ventilation.

${ }^{*} P<0.05,{ }^{* *} P<0.001$.

Description of the determinants: sex was coded as $1=$ female, $2=$ male. Type of $\mathrm{SCl}$ score was coded as $1=$ tetraplegia, $2=$ paraplegia. Completeness of the lesion was coded as $1=$ complete injury, $2=$ incomplete injury. AIS score was coded as $1=A, 2=B, 3=C, 4=D$. Neurologic level of injury was coded as $1=\mathrm{C} 3-\mathrm{C} 8$ level, $2=\mathrm{T} 1-\mathrm{T} 6$ level, $3=\mathrm{T} 7-\mathrm{T} 12$ level, $4=\mathrm{L} 1-\mathrm{L} 4$ level. Ambulation level was coded as $1=$ non-ambulatory, $2=$ ambulatory. All the statistically significant values are written in bold.

\section{DISCUSSION}

This study demonstrated that the reduced lung function measures including FVC, FEV1 and MVV were significant predictors of DM and 
Table 4 Logistic regression analysis for DM

\begin{tabular}{|c|c|c|c|c|c|c|c|}
\hline \multirow[t]{2}{*}{ Variable } & \multirow[t]{2}{*}{$\beta$} & \multirow[t]{2}{*}{$S E$} & \multirow[t]{2}{*}{ Wald } & \multirow[t]{2}{*}{ P-value } & \multirow[t]{2}{*}{$\operatorname{Exp} \beta(O R)$} & \multicolumn{2}{|c|}{$95 \% \mathrm{Cl}$ for $O R$} \\
\hline & & & & & & Lower bound & Upper bound \\
\hline Age & 0.061 & 0.015 & 17.896 & 0.000 & 1.063 & 1.034 & 1.094 \\
\hline BMI & 0.126 & 0.055 & 5.292 & 0.021 & 1.134 & 1.019 & 1.262 \\
\hline Ambulation level Ambulatory (ref.) & 1.304 & 0.493 & 6.990 & 0.008 & 3.683 & 1.401 & 9.683 \\
\hline MVV & -0.031 & 0.012 & 6.610 & 0.010 & 0.970 & 0.947 & 0.993 \\
\hline FEV1 & -1.094 & 0.445 & 6.053 & 0.014 & 0.335 & 0.140 & 0.801 \\
\hline FVC & -0.938 & 0.389 & 5.821 & 0.016 & 0.391 & 0.183 & 0.839 \\
\hline
\end{tabular}

Abbreviations: BMI, body mass index; Cl, confidence interval; DM, diabetes mellitus; FEV1, forced expiratory volume in 1 s; FVC, forced vital capacity; MVV, maximum voluntary ventilation; $\mathrm{OR}$, odds ratio.

$\mathrm{R}^{2}$ Nagelkerke: 0.276 .

Table 5 Logistic regression analysis for hypertension

\begin{tabular}{|c|c|c|c|c|c|c|c|}
\hline \multirow[t]{2}{*}{ Variable } & \multirow[t]{2}{*}{$\beta$} & \multirow[t]{2}{*}{$S E$} & \multirow[t]{2}{*}{ Wald } & \multirow[t]{2}{*}{ P-value } & \multirow{2}{*}{$\begin{array}{c}\operatorname{Exp} \beta \\
(O R)\end{array}$} & \multicolumn{2}{|c|}{$95 \% \mathrm{Cl}$ for $O R$} \\
\hline & & & & & & $\begin{array}{l}\text { Lower } \\
\text { bound }\end{array}$ & $\begin{array}{l}\text { Upper } \\
\text { bound }\end{array}$ \\
\hline Age & 0.079 & 0.014 & 31.930 & 0.000 & 1.082 & 1.053 & 1.112 \\
\hline BMI & 0.195 & 0.051 & 14.638 & 0.000 & 1.215 & 1.100 & 1.342 \\
\hline MVV & -0.019 & 0.008 & 4.948 & 0.026 & 0.981 & 0.965 & 0.998 \\
\hline FEV1 & -0.729 & 0.320 & 5.195 & 0.023 & 0.483 & 0.258 & 0.903 \\
\hline FVC & -0.600 & 0.278 & 4.666 & 0.031 & 0.549 & 0.319 & 0.946 \\
\hline
\end{tabular}

Abbreviations: $\mathrm{BMI}$, body mass index; $\mathrm{Cl}$, confidence interval; $\mathrm{FEV} 1$, forced expiratory volume in $1 \mathrm{~s}$; FVC, forced vital capacity; MVV, maximum voluntary ventilation; OR, odds ratio.

$R^{2}$ Nagelkerke: 0.354 .

hypertension in chronic SCI patients. A recent literature survey confirms that this is the first study that investigated the association between reduced lung function and CVD risk factors including hypertension and DM in the SCI population.

FRS is a valid score for CVD risk estimation and has been used in multiple ethnic group investigations, as well as in the SCI population. ${ }^{1,25-27}$ Although the FRS model is commonly used to predict CVD risk in people with SCI, the population-specific factors such as physical inactivity and reduced aerobic fitness, obesity and increased adiposity, autonomous system impairment and inflammatory risk markers are not incorporated in this model. Thus, it has been suggested that FRS may underestimate the CVD risk in the SCI population. ${ }^{25}$ To date, despite the disadvantages of this general risk estimation model, a SCI-specific CVD risk prediction model has not been developed.

Two studies have reported that one-third of people with paraplegia had moderate-to-high risk for CVD and required therapeutic intervention according to FRS. ${ }^{1,25}$ Two other recent studies also found that 15.6 and $10 \%$ of the patients with paraplegia and quadriplegia had moderate-to-high risk for CVD by using FRS, respectively. ${ }^{26,30}$

According to the FRS guideline, $\sim 6.7 \%$ of our patients had high risk, $5.9 \%$ of them had intermediate risk and $77.1 \%$ of the study group had low risk for CVD. In total, $12.6 \%$ of our SCI patients were identified as requiring therapeutic intervention.

The Framingham heart study 31,32 and other authoritative guidelines 33,34 reported that HDL is an independent and inverse coronary risk factor. Furthermore, low HDL predicts an increased incidence of CVD independent of other risks including a high low- density-lipoprotein level. ${ }^{31,32}$ To date, a low HDL level is accepted as one of the major risk factors for CVD in able-bodied population, ${ }^{2-4,6}$ and it has been found as depressed in the SCI population..$^{2-5,20,26}$ In the present study, most of our patients (85\%) had a low HDL level.

Low HDL level in the SCI population has been explained by lower physical activity and immobilization..$^{2-5,26}$ Furthermore, a significant inverse relationship has been found between the degree of neurologic deficit and mean serum HDL in these patients. ${ }^{2}$ Correlating with these explanations, we showed that a higher neurologic level of injury and wheelchair dependency were significant predictors of a low HDL level in our SCI population.

Therapeutic interventions include low-saturated-fat and lowcholesterol diet, smoking cessation, physical activity, weight control and the medications that are the cornerstones of treatment for lowering CVD risk in able-bodied population. ${ }^{2,20}$ Although nearly $12.6 \%$ of our patients were identified as requiring therapeutic intervention by using FRS and $85 \%$ of them had Low HDL as an independent coronary risk factor, most of our SCI patients were not receiving specific interventions for lowering CVD risk at the time of the study. Little attention seems to be paid to the modifiable CVD risk factors, probably because these patients are free from CVD symptoms or disease.

Both cross-sectional and longitudinal studies have reported that the reduced lung function parameters are associated with an increased risk for the future development of prediabetes/DM in the general population, independent of age, BMI, smoking, exercise and alcohol use. $^{14,15,21,35-37}$ Furthermore, impaired lung function presents before the development of diabetes. ${ }^{14,15,21,36,38,39}$

The metabolic stage between normal glucose homeostasis and DM is called prediabetes, and this stage is presented with increased fasting glucose or impaired glucose tolerance. ${ }^{40}$ Prediabetes is a risk factor for CVD. ${ }^{41}$ It has been observed that $30 \%$ of the subjects with prediabetes developed DM during the 3-5-year follow-up.

Although the exact mechanism for the association between reduced lung function and prediabetes/DM is clearly not known, possible mechanisms for the link between lower lung function and prediabetes/DM have been suggested as hypoxemia-induced insulin resistance, a common inflammatory process and a low level of respiratory muscle strength. ${ }^{14,21}$

Reduced lung function is associated with a diminished capacity of maximum oxygen uptake, which is considered to be the best measure of cardiorespiratory fitness and exercise capacity. Reduced exercise capacity eventually results in insulin resistance and DM. ${ }^{21}$ Reduced lung function is also associated with systemic inflammation in the general population. ${ }^{42,43}$ Some previous studies indicated that 
Table 6 Logistic regression analysis for low HDL level

\begin{tabular}{|c|c|c|c|c|c|c|c|}
\hline \multirow[t]{2}{*}{ Variable } & \multirow[t]{2}{*}{$\beta$} & \multirow[t]{2}{*}{$S E$} & \multirow[t]{2}{*}{ Wald } & \multirow[t]{2}{*}{ P-value } & \multirow[t]{2}{*}{$\operatorname{Exp} \beta(O R)$} & \multicolumn{2}{|c|}{$95 \% \mathrm{Cl}$} \\
\hline & & & & & & Lower bound & Upper bound \\
\hline Female (ref.) & -2.314 & 0.397 & 33.977 & 0.000 & 0.099 & 0.045 & 0.215 \\
\hline \multicolumn{8}{|c|}{ Neurologic level of injury L1-L4 level (ref.) } \\
\hline Ambulation level Ambulatory (ref.) & 1.179 & 0.405 & 8.471 & 0.004 & 3.252 & 1.470 & 7.196 \\
\hline
\end{tabular}

Abbreviations: $\mathrm{Cl}$, confidence interval; $\mathrm{HDL}$, high-density lipoprotein; OR, odds ratio.

$R^{2}$ Nagelkerke: 0.343

Table 7 Factors affected on FRS by multiple linear regression analysis

\begin{tabular}{|c|c|c|c|c|c|c|}
\hline & $\beta$ & $S E$ & P-value & Lower bound & Upper bound & $\mathrm{R}^{2}$ \\
\hline \multicolumn{7}{|l|}{ Framingham Risk Score } \\
\hline Age & 0.273 & 0.039 & 0.000 & 0.195 & 0.351 & 0.491 \\
\hline Sex & 3.217 & 1.195 & 0.008 & 0.852 & 5.581 & \\
\hline Type of spinal cord injury Score & -3.263 & 1.631 & 0.048 & -6.489 & -0.036 & \\
\hline Neurologic level of injury & 1.853 & 0.685 & 0.008 & 0.499 & 3.208 & \\
\hline $\mathrm{BMI}$ & -0.096 & 0.107 & 0.373 & -0.308 & 0.116 & \\
\hline FEV1 & -0.215 & 1.900 & 0.910 & -3.973 & 3.544 & \\
\hline FVC & 0.438 & 1.588 & 0.783 & -2.704 & 3.581 & \\
\hline MVV & -0.049 & 0.019 & 0.013 & -0.087 & -0.011 & \\
\hline
\end{tabular}

Abbreviations: AIS, American Spinal Injury Association Impairment Scale; BMI, body mass index; Cl, confidence interval; FEV1, forced expiratory volume in 1 s; FRS, Framingham Risk Score; FVC, forced vital capacity; MVV, maximum voluntary ventilation. Bold entries indicate the statistically significant values.

$R^{2}$ : 0.491. Adjusted $R^{2}: 0.448$

proinflammatory cytokines such as CRP, fibrinogen and IL-6 may have a role in the pathogenesis of DM. ${ }^{14,36}$

Cohort studies have shown that the reduced lung function parameters are strong, inverse predictors for the future development of hypertension in the able-bodied population. ${ }^{14,16,17,19,22,44,45}$ In addition, it has been reported that, although the changes in lung function were predictive of incident hypertension, changes in blood pressure were not predictive of loss of lung function. ${ }^{19}$ Furthermore, it has been found that the incidence of CVD and death associated with hypertension is increased in the presence of reduced lung function. ${ }^{46,47}$

Although the reasons for the association between the reduced lung function and hypertension are not clearly known, it has been speculated that the loss of lung elastic recoil, reduced chest wall compliance and decreased respiratory muscle strength may be paralleled by a nonatherosclerotic reduction in vascular elasticity that results in an increase in arterial blood pressure. ${ }^{48}$

Epidemiological studies have also determined an association between reduced lung function and increased levels of markers of inflammation in healthy subjects. ${ }^{42,43}$ Inflammation may also affect the arterial system and cause the development of hypertension. Indeed, a relationship between the CRP and arterial stiffness has been shown in asymptomatic subjects. ${ }^{49,50} \mathrm{CRP}$ has also been found to be elevated in both acute and chronic SCI. ${ }^{3,51}$

Because of denervation of the respiratory pump respiratory muscle strength is reduced after the onset of SCI. MVV is used as an index of inspiratory muscle strength. ${ }^{52,53}$ Of all of our patients with SCI, 55.7\% of them had a MVV $<80 \%$ of the predicted maximum. This finding pointed out that more than half of our patients have evident respiratory muscle weakness. Moreover, reduced inspiratory muscle force immediately after the injury causes lower lung volumes and flow rates. Of all study groups, $64 \%$ of our patients had reduced FVC and $53.7 \%$ of them had reduced FEV1 values. We suggest that impaired lung function occurring right after the injury may contribute to early development of hypertension and DM, which may eventually lead to premature CVD in SCI population.

The current study has some limitations. First, the design of the study does not allow determination of whether the long-term changes in lung functions are associated with hypertension and DM in the SCI population. Also, the risk of CVD may have been influenced by early lifestyle factors, which could not have been investigated in this study.

The sample size was relatively small, and the data used were obtained only from one rehabilitation hospital. In addition, it might be perceived as if there is some form of selection bias present in our 
study, and our sample is a biased representative for the population of all former inpatients. However, this is not the case, and there is no presence of selection bias as our hospital regularly readmits of all former patients for a follow-up treatment as further explained in the following.

Currently, in Turkey, there are only a few optimal rehabilitation hospitals providing comprehensive rehabilitation services to the patients needing rehabilitation interventions. Furthermore, these centers are located only in a few major cities. Our academic rehabilitation hospital is the biggest inpatient rehabilitation hospital of Turkey. Therefore, we accept patients from each and every village, town and city across Turkey.

Because of the fact that there is only a limited number of optimal rehabilitation centers in Turkey and also most of the patients with SCI have to travel long distances to attend these hospitals from their hometowns, the patients are re-admitted for inpatient rehabilitation to the centers as many times as needed in order to evaluate, control, prevent, treat and rehabilitate acute and chronic medical conditions/ complications seen in SCI patients. Thus, our sample is an unbiased representative for patients with SCI, and there is no presence of selection bias.

Some of our conclusions are limited based on the grounds that this study was a retrospective study design of medical files and also might constitute a potential for temporality bias in our study. Although the conclusions of the study are based on sound data and the methodologies, further prospective studies are necessary to generalize the conclusions of this study.

Despite the fact that our study demonstrated that reduced lung function parameters were significant predictors of DM and hypertension in chronic SCI patients, it is hard to say definitively that the development of DM and hypertension were solely resulted from lower lung function seen in these population. Our results also showed that other factors such as age, obesity and ambulation levels in addition to the lower lung function might have contributed to the risk of DM and hypertension.

In conclusion, this study showed that there might be a significant relationship between reduced lung function and the risk of DM and hypertension in people with SCI. Therefore, systematic measurement of these parameters should be performed in the routine clinical follow-up of SCI patients. Once reduced lung parameters are determined, the higher risk for developing hypertension and DM should be considered and a comprehensive rehabilitation program including appropriate intervention strategies for CVD should be applied in this population who may have few treatment options.

\section{DATA ARCHIVING}

There were no data to deposit.

\section{CONFLICT OF INTEREST}

The authors declare no conflict of interest.

1 Wahman K, Nash MS, Lewis JE, Seiger Å, Levi R. Cardiovascular disease risk and the need for prevention after paraplegia determined by conventional multifactorial risk models: the Stockholm spinal cord injury study. J Rehabil Med 2011; 43: 237-242.

2 Svircev JN. Cardiovascular disease in persons with spinal cord dysfunction - an update on select topics. Phys Med Rehabil Clin North Am 2009; 20: 737-747.

3 Myers J, Lee M, Kiratli J. Cardiovascular disease in spinal cord injury: an overview of prevalence, risk, evaluation, and management. Am J Phys Med Rehabil 2007; 86: 142-152.

4 Bauman W, Spungen A. Risk assessment for coronary heart disease in a veteran population with spinal cord injury. Top Spinal Cord Inj Rehabil 2007; 12: 35-53.
5 Warburton DE, Sproule S, Krassioukov A \& Eng JJ. Cardiovascular health and exercise following spinal cord injury. In: Eng JJ, Teasell RW, Miller WC, Wolfe DL, Townson AF, Hsieh JTC (eds). Spinal Cord Injury Rehabilitation Evidence. Version 2.0. ICORD, Vancouver, 2006; pp 7.1-7.34.

6 Bauman W, Spungen A. Coronary heart disease in individuals with spinal cord injury: assessment of risk factors. Spinal Cord 2008; 46: 466-476.

7 Garshick E, Kelley A, Cohen SA, Garrison A, Tun CG, Gagnon D et al. A prospective assessment of mortality in chronic spinal cord injury. Spinal Cord 2005; 43: 408-416.

8 Vázquez RG, Sedes PR, Fariña MM, Marqués AM, Velasco MEF. Respiratory management in the patient with spinal cord injury. BioMed Res Int 2013; 2013: 168757.

9 Arora S, Flower O, Murray NP, Lee BB. Respiratory care of patients with cervical spinal cord injury: a review. Crit Care Resusc 2012; 14: 64-73.

10 Jain NB, Brown R, Tun CG, Gagnon D, Garshick E. Determinants of forced expiratory volume in 1 second (FEV 1), forced vital capacity (FVC), and FEV 1/FVC in chronic spinal cord injury. Arch Phys Med Rehabil 2006; 87: 1327-1333.

11 Stolzmann KL, Gagnon DR, Brown R, Tun CG, Garshick E. Longitudinal change in FEV1 and FVC in chronic spinal cord injury. Am J Resp Critical Care Med 2008; 177: 781-786.

12 Sheel AW, Reid WD, Townson A \& Ayas N. Respiratory management following spinal cord injury. In: Eng JJ, Teasell RW, Miller WC, Wolfe DL, Townson AF, Hsieh JTC (eds). Spinal Cord Injury Rehabilitation Evidence. Version 5.0. ICORD, Vancouver, 2014, pp $1-55$.

13 Postma K, Haisma JA, de Groot S, Hopman MT, Bergen MP, Stam HJ et al. Changes in pulmonary function during the early years after inpatient rehabilitation in persons with spinal cord injury: a prospective cohort study. Arch Phys Med Rehabil 2013; 94 : 1540-1546.

14 Wannamethee SG, Shaper AG, Rumley A, Sattar N, Whincup PH, Thomas MC et al. Lung function and risk of type 2 diabetes and fatal and nonfatal major coronary heart disease events: possible associations with inflammation. Diabetes Care 2010; 33: 1990-1996.

15 Ford ES, Mannino DM. Prospective association between lung function and the incidence of diabetes findings from the National Health and Nutrition Examination Survey Epidemiologic Follow-Up Study. Diabetes Care 2004; 27: 2966-2970.

16 Karunanayake CP, Rennie DC, Pahwa P, Chen Y, Dosman JA. Relationship between lung function and hypertension among rural Canadians using fractional polynomials. Sri Lankan Journal of Applied Statistics 2012; 12: 41-61.

17 Wu Y, Vollmer WM, Buist AS, Tsai R, Cen R, Wu X et al. Relationship between lung function and blood pressure in Chinese men and women of Beijing and Guangzhou. Int J Epidemiol 1998; 27: 49-56.

18 Schnabel E, Nowak D, Brasche S, Wichmann H-E, Heinrich J. Association between lung function, hypertension and blood pressure medication. Respir Med 2011; 105: 727-733.

19 Jacobs DR, Yatsuya $H$, Hearst MO, Thyagarajan B, Kalhan R, Rosenberg S et al. Rate of decline of forced vital capacity predicts future arterial hypertension: The Coronary Artery Risk Development in Young Adults Study. Hypertension 2012; 59: 219-225.

20 Nash MS, Mendez AJ. A guideline-driven assessment of need for cardiovascular disease risk intervention in persons with chronic paraplegia. Arch Phys Med Rehabil 2007; 88: 751-757.

21 Yamane T, Yokoyama A, Kitahara Y, Miyamoto S, Haruta Y, Hattori N et al. Cross-sectional and prospective study of the association between lung function and prediabetes. BMJ Open 2013; 3: e002179.

22 Sparrow D, Weiss ST, Vokonas PS, Cupples LA, Ekerdt DJ, Colton T. Forced vital capacity and the risk of hypertension the normative aging study. Am J Epidemiol 1988; 127: 734-741.

23 Lee JY, Ahn SV, Choi DP, Suh M, Kim HC, Kim YS et al. Association between hypertension and pulmonary function in rural adults in Korea. J Prev Med Public Health 2009; 42: 21-28.

24 Expert Panel on Detection. Executive summary of the third report of the National Cholesterol Education Program (NCEP) expert panel on Detection, Evaluation, and Treatment of high blood cholesterol in adults (Adult Treatment Panel III). JAMA 2001; 285: 2486

25 Finnie AK, Buchholz AC, Martin Ginis KA. Current coronary heart disease risk assessment tools may underestimate risk in community-dwelling persons with chronic spinal cord injury. Spinal Cord 2008; 46: 608-615.

26 Vichiansiri R, Saengsuwan J, Manimmanakorn N, Patpiya S, Preeda A, Samerduen K et al. The prevalence of dyslipidemia in patients with spinal cord lesion in Thailand. Cholesterol 2012; 2012: 847462.

27 D'Agostino RB Sr, Grundy S, Sullivan LM, Wilson P. Validation of the Framingham coronary heart disease prediction scores: results of a multiple ethnic groups investigation. JAMA 2001; 286: 180-187.

28 Expert Committee on the Diagnosis and Classification of Diabetes Mellitus. Report of the expert committee on the diagnosis and classification of diabetes mellitus. Diabetes Care 2003; 26: S5-S20.

29 Gupta N, White KT, Sandford PR. Body mass index in spinal cord injury-a retrospective study. Spinal Cord 2006; 44: 92-94.

30 Hussain A, Qureshi AZ, Ayaz SB, Rathore FA. Framingham Risk Scores for coronary heart disease in a cohort of Saudi Arabian men and women with spinal cord injury. Acta Neurologica Belgica 2016; 116, 179-184.

31 Castelli WP, Anderson K, Wilson PW, Levy D. Lipids and risk of coronary heart disease The Framingham Study. Ann Epidemiol 1992; 2: 23-28.

32 Nam B-H, Kannel WB, D'Agostino RB. Search for an optimal atherogenic lipid risk profile from the Framingham Study. Am J Cardiol 2006; 97: 372-375. 
33 Assmann G, Schulte H, von Eckardstein A, Huang Y. High-density lipoprotein cholesterol as a predictor of coronary heart disease risk. The PROCAM experience and pathophysiological implications for reverse cholesterol transport. Atherosclerosis 1996; 124: S11-S20.

34 Frick MH, Elo O, Haapa K, Heinonen OP, Heinsalmi P, Helo P et al. Helsinki Heart Study: primary-prevention trial with gemfibrozil in middle-aged men with dyslipidemia. N Engl J Med 1987; 317: 1237-1245.

35 Kwon C-H, Rhee EJ, Song JU, Kim JT, Kwag HJ, Sung KC et al. Reduced lung function is independently associated with increased risk of type 2 diabetes in Korean men. Cardiovasc Diabetol 2012; 11: 38.

36 Yeh F, Dixon AE, Marion S, Schaefer C, Zhang Y, Best LG et al. Obesity in adults is associated with reduced lung function in metabolic syndrome and diabetes: the Strong Heart Study. Diabetes Care 2011; 34: 2306-2313.

37 Engström G, Hedblad B, Nilsson P, Wollmer P, Berglund G, Janzon L et al. Lung function, insulin resistance and incidence of cardiovascular disease: a longitudinal cohort study. J Intern Med 2003; 253: 574-581.

38 van den Borst B, Gosker HR, Zeegers MP, Schols AM. Pulmonary function in diabetes: a metaanalysis. CHEST J 2010; 138: 393-406.

39 Yeh H-C, Punjabi NM, Wang NY, Pankow JS, Duncan BB, Cox CE et al. Cross-sectional and prospective study of lung function in adults with type 2 diabetes: the Atherosclerosis Risk in Communities (ARIC) Study. Diabetes Care 2008; 31: 741-746.

40 World Health Organization. Definition and diagnosis of diabetes mellitus and intermediate hyperglycaemia: WHO report. Report of a WHO/IDF consultation, pp 1-50, 2006. http://www.who.int/diabetes/publications/Definition\%20and\%20 diagnosis\%20of\%20diabetes_new.pdf. Accessed 14 January 2006.

41 Qiao Q, Jousilahti P, Eriksson J, Tuomilehto J. Predictive properties of impaired glucose tolerance for cardiovascular risk are not explained by the development of overt diabetes during follow-up. Diabetes C are 2003; 26: 2910-2914.

42 Fogarty AW, Jones S, Britton JR, Lewis SA, McKeever TM. Systemic inflammation and decline in lung function in a general population: a prospective study. Thorax 2007; 62 : 515-520.
43 Kalhan R, Tran BT, Colangelo LA, Rosenberg SR, Liu K, Thyagarajan B et al. Systemic inflammation in young adults is associated with abnormal lung function in middle age. PLOS ONE 2010; 5: e11431.

44 Lee H, Le H, Lee B, Lopez V, Wong N. Forced vital capacity paired with Framingham Risk Score for prediction of all-cause mortality. Eur Respir J 2010; 36: 1002-1006.

$45 \mathrm{Sin}$ DD, Wu L, Man SP. The relationship between reduced lung function and cardiovascular mortality: a population-based study and a systematic review of the literature. CHEST J 2005; 127: 1952-1959.

46 Schunemann HJ, Dorn J, Grant BJ, Winkelstein W, Trevisan M. Pulmonary function is a long-term predictor of mortality in the general population: 29-year follow-up of the Buffalo Health Study. CHEST J 2000; 118: 656-664.

47 Engström G, Hedblad B, Valind S, Janzon L. Increased incidence of myocardial infarction and stroke in hypertensive men with reduced lung function. J Hypertens 2001; 19: 295-301.

48 Peralta CA, Adeney KL, Shlipak MG, Jacobs D Jr, Duprez D, Bluemke D et al. Structural and functional vascular alterations and incident hypertension in normotensive adults: the Multi-Ethnic Study of Atherosclerosis. Am J Epidemiol 2010; 171: 63-71.

49 Armstrong EJ, Morrow DA, Sabatine MS. Inflammatory biomarkers in acute coronary syndromes part II: acute-phase reactants and biomarkers of endothelial cell activation. Circulation 2006; 113: e152-e155.

50 Duprez D, Somasundaram PE, Sigurdsson G, Hoke L, Florea N, Cohn JN. Relationship between $\mathrm{C}$-reactive protein and arterial stiffness in an asymptomatic population. J Hum Hypertens 2005; 19: 515-519.

51 Garshick E, Stolzmann KL, Gagnon DR, Morse LR, Brown R. Systemic inflammation and reduced pulmonary function in chronic spinal cord injury. PM\&R 2011; 3: 433-439.

52 Neder JA, Andreoni S, Lerario M, Nery L. Reference values for lung function tests: II. Maximal respiratory pressures and voluntary ventilation. Brazil J Med Biol Res 1999; 32: 719-727.

53 Ries AL. The importance of exercise in pulmonary rehabilitation. Clin Chest Med 1994; 15: 327-337. 